\title{
Soluble nickel interferes with cellular iron homeostasis
}

\author{
Todd Davidson, ${ }^{1}$ Haobin Chen, ${ }^{1}$ Michael D. Garrick, ${ }^{2}$ \\ Gisela D'Angelo ${ }^{3}$ and Max Costa ${ }^{1}$
}

${ }^{1}$ Nelson Institute of Environmental Medicine, New York University, School of Medicine, Tuxedo, New York, USA; ${ }^{2}$ Department of Biochemistry, SUNY, Buffalo, New York, USA; ${ }^{3}$ Neurobiologie Vasculaire, INSERM U615, Université de Nice Sophia Antipolis, Parc, Valrose, Nice, France

\begin{abstract}
Soluble nickel compounds are likely human carcinogens. The mechanism by which soluble nickel may contribute to carcinogenesis is unclear, though several hypotheses have been proposed. Here we verify the ability of nickel to enter the cell via the divalent metal ion transporter 1 (DMT1) and disturb cellular iron homeostasis. Nickel may interfere with iron at both an extracellular level, by preventing iron from being transported into the cell, and at an intracellular level, by competing for iron sites on enzymes like the prolyl hydroxylases that modify hypoxia inducible factor- $1 \alpha$ (HIF-1 $\alpha)$. Nickel was able to decrease the binding of the Von Hippel-Lindau (VHL) protein to HIF-1 $\alpha$, indicating a decrease in prolyl hydroxylase activity. The ability of nickel to affect various iron dependent processes may be an important step in nickel dependent carcinogenesis. In addition, understanding the mechanisms by which nickel activates the HIF-1 $\alpha$ pathway may lead to new molecular targets in fighting cancer. (Mol Cell Biochem 279: 157-162, 2005)
\end{abstract}

Key words: divalent metal ion transporter-1, HIF-1 $\alpha$, iron, nickel, prolyl hydroxylase, Von Hippel-Lindau

\section{Introduction}

Humans come in contact with metals on a daily basis via both environmental and occupational exposures [1]. Though not all metals are known to cause cancer, nickel compounds have been shown to be carcinogenic by in vitro, in vivo and epidemiological studies [2]. Nickel compounds transform cells in culture, as well as produce tumors at the site of injection in a variety of experimental animals. The main route of human exposure to nickel compounds is via inhalation and consequently, workers occupationally exposed to nickel have higher rates of lung and nasal cancers [3,4]. Several mechanisms, including epigenetic effects, signaling and interference with iron dependent processes, have been proposed to explain the carcinogenic effects of nickel, though the extent that each may play remains to be determined.

One of the key factors in assessing the carcinogenicity of a given nickel compound is its solubility. Water insoluble nickel compounds like nickel subsulfide are extremely carcinogenic when compared to water soluble nickel compounds like nickel chloride [5]. Nevertheless, recent epidemiological evaluations have suggested that soluble nickel compounds are likely carcinogenic to humans as well [6-8].

If nickel must enter cells to be carcinogenic, then the uptake of nickel compounds may be another important factor in determining potential toxicity and carcinogenicity. While insoluble nickel compounds can be taken up by phagocytosis, the mechanism of uptake for soluble nickel 
compounds is less defined. Hediger and colleagues showed that a variety of metals, including nickel, elicited an inward current when they used expression cloning of divalent metal ion transporter 1 (DMT1) in oocytes of Xenopus laevis. [9]. In addition to possibly being able to transport nickel, DMT1 is involved in iron uptake via both transferrin receptor (TfR)-dependent and TfR-independent mechanisms [9-12]. We have recently shown that nickel competes with iron for uptake via DMT1 and probably other transporters [13]. By competing for iron uptake into cells, nickel decreases cellular iron levels, decreases aconitase activity and increases iron regulatory protein-1 (IRP-1) binding activity [13]. In addition, interference with iron metabolism may have effects on other iron dependent processes in the cell.

Various enzymes in the cell utilize iron, including the prolyl hydroxylases (PHD1-3) and the aspargine hydroxylase (FIH-1) that control the stability and transcriptional activity of HIF-1 $\alpha$, respectively [14-16]. Nickel stabilizes HIF$1 \alpha$, which is probably a result of interference with these enzymes [17]. PHD1-3 and FIH-1 are members of an iron and 2-oxoglutarate dependent dioxygenase family that also require oxygen and ascorbic acid for enzymatic activity. Under normoxic conditions, PHD1-3 can hydroxylate HIF- $1 \alpha$ at Pro402 and Pro564 in the oxygen-dependent degradation domain (ODD) of HIF-1 $\alpha$, while FIH-1 can hydroxylate Asp803 in the COOH-terminal region (CAD) of HIF- $1 \alpha$. These posttranslational modifications lead to degradation of HIF- $1 \alpha$ mediated by Von Hippel-Lindau protein (VHL) and prevent transactivation of HIF-1 target genes. Under conditions where oxygen, iron, ascorbic acid, or 2-oxoglutarate are low or inaccessible, PHD1-3 and FIH-1 lose enzymatic activity. This loss leads to the stabilization of HIF- $1 \alpha$ protein and recruitment of $\mathrm{p} 300$, which is involved in the transactivation of HIF-1 target genes. When stabilized, HIF- $1 \alpha$ forms a heterodimer with HIF-1 $\beta /$ ARNT to form the transcription factor HIF-1, which activates a variety of target genes including genes involved in angiogenesis, glucose metabolism, cell survival, and erythropoiesis [18]. Interestingly, HIF- $1 \alpha$ is overexpressed in many types of cancers and provides an attractive link between nickel and cancer [19, 20].

In this paper we show that nickel can enter the cell via DMT1. The transport of nickel via DMT1 provides a mechanism by which nickel can interfere with iron homeostasis. We then present evidence that nickel can prevent transferrin bound iron and non-transferrin bound iron from entering the cell. In addition, we demonstrate that the stabilization of HIF- $1 \alpha$ may be a result of nickel's interference with the prolyl hydroxylases that regulate HIF- $1 \alpha$. In general, nickel alters iron metabolism in the cell, alterations which may provide a potential mechanism for nickel to transform a normal cell.

\section{Materials and methods}

\section{Chemicals}

All reagents were obtained from Sigma (St. Louis, MO) unless otherwise specified. ${ }^{63} \mathrm{Ni}\left(\mathrm{NiCl}_{2}\right)$ was purchased from Perkin Elmer (Boston, MA).

\section{Cell culture}

Human lung A549 cells were grown in Ham's F-12 K medium (Gibco BRL, Grand Island, NY). HEK293 cells permanently transfected with a tetracycline inducible empty vector or vector containing a rat DMT1 construct (encoding the protein isoform that starts with exon 2 and terminates in exon 17 , the exon that lacks an iron responsive element) were grown in DMEM medium. DMEM and F-12 K were both supplemented with $10 \%$ fetal bovine serum and $1 \%$ penicillin/streptomycin, though only DMEM received $600 \mu \mathrm{g} / \mathrm{ml}$ G418 and $200 \mu \mathrm{g} / \mathrm{ml}$ hygromycin. To induce expression of DMT1, $2.5 \mathrm{ng} / \mathrm{ml}$ of doxycycline were added $24 \mathrm{~h}$ prior to nickel treatment. Cells were maintained at $37^{\circ} \mathrm{C}$ in a humidified $5 \% \mathrm{CO}_{2}$ atmosphere. All treatments were performed when cell density reached approximately $80 \%$ confluency.

${ }^{63} \mathrm{Ni}$ uptake

A549 cells expressing endogenous transporters, HEK cells permanently transfected with a tetracycline inducible expression vector for DMT1, or control HEK cells transfected with an empty vector were grown in 6 well dishes. Twenty-four hours prior to metal exposure, one set of HEK cells was exposed to doxycycline to induce DMT1 expression. At the start of the experiment, the cell medium was removed and cells were washed twice with prewarmed HEPES buffered saline solution (HBSS) $\left(\mathrm{pH} 7.4,37^{\circ} \mathrm{C}\right) .1 .5 \mathrm{ml}$ of prewarmed HBSS ( $\mathrm{pH} 6.0,37^{\circ} \mathrm{C}$ ) containing ${ }^{63} \mathrm{Ni}$ was then added to each well. Cells were then incubated for various times at $37^{\circ} \mathrm{C}$ in a water bath. After incubation, cells were removed from the water bath and placed on ice. The media was immediately removed and ice cold "stop buffer" (HBSS with $20 \mathrm{mM}$ 2-deoxyglucose and $10 \mathrm{mM}$ sodium fluoride, $\mathrm{pH}$ 7.4) was added. Stop buffer was then removed and cells were washed three times with HBSS containing $1 \mathrm{mM}$ EDTA to remove membrane bound nickel. Cells were then solubilized in $1 \%$ SDS and radioactivity was then counted on a Wallac Liquid Scintillation Counter Model 1409. All uptake experiments were repeated three times.

\section{Western blots}

A549 cells were cultured in $60 \mathrm{~cm}$ dishes to approximately $80 \%$ confluency. Cells were then treated with $\mathrm{NiCl}_{2}, \mathrm{FeSO}_{4}$, 
holo-transferrin, or $\mathrm{NiCl}_{2}$ plus one of the iron compounds for $24 \mathrm{~h}$. Cells were then scraped in PBS with a rubber policeman and collected in $15 \mathrm{ml}$ tubes. Cells were spun down for $5 \mathrm{~min}$ at $1200 \mathrm{rpm}$ and the supernatant was removed. The cell pellet was then resuspended in lysis buffer $(50 \mathrm{mM}$ Tris- $\mathrm{HCl}$, 5 mM EDTA, $150 \mathrm{mM} \mathrm{NaCl}_{2}, 2 \%$ NP-40) supplemented with complete protease inhibitor cocktail (EDTA free) (Roche). The suspensions were then placed on ice for $20 \mathrm{~min}$ and then spun down at $13,000 \times g$ for $15 \mathrm{~min}$. The remaining supernatant was collected and used for Western blotting. Thirty $\mu \mathrm{g}$ of protein were electrophoresed on a $15 \%$ SDS-PAGE gel and transferred to a PVDF membrane. Immunoblotting was performed with diluted ferritin light chain antibody (1:300) (Santa Cruz Biotechnology, Santa Cruz, CA). Detection was accomplished by following an $\mathrm{ECL}^{\mathrm{TM}}$ Western blotting protocol (Amersham).

\section{VHL binding assay}

The VHL binding assay was performed as previously described [21]. Briefly glutathione-purified ODD was combined with cell extract from control and nickel treated cells in reaction buffer at $37^{\circ} \mathrm{C}$ for $30 \mathrm{~min}$. The reaction products were incubated with approximately $50,000 \mathrm{dpm}$ of ${ }^{35} \mathrm{~S}$ labelled VHL protein for $2 \mathrm{~h}$ at $4{ }^{\circ} \mathrm{C}$. Beads were then washed four times in NTEN buffer and bound proteins were eluted by boiling in SDS running buffer. ${ }^{35} \mathrm{~S}$-labelled VHL protein was visualized in a $15 \%$ gel with ENLIGHTNING solution (Perkin Elmer).

\section{Results}

\section{Soluble nickel can be taken up into cells by DMT1}

The uptake of ${ }^{63} \mathrm{Ni}$ into A549 cells, expressing only endogenous transporters was measured to learn if soluble nickel entered cells (Fig. 1a). The data show that soluble nickel enters cells. For approximately the first minute, nickel is rapidly taken up into the cells but after one minute, the uptake slowed down, and nickel uptake gradually began to plateau. In order to reveal if transport by DMT1 was a possible mechanism by which nickel could enter cells, we asked whether a human embryonic kidney (HEK) cell line with a tetracycline inducible expression vector containing DMT1 exhibited increased incorporation when induced to express this transporter compared to uninduced cells or those with an empty vector. We then measured ${ }^{63} \mathrm{Ni}$ uptake in these cell lines (Fig. 1b). When DMT1 was overexpressed, the uptake of nickel was significantly increased over both the control and non-induced cell line. The uptake of ${ }^{63} \mathrm{Ni}$ in the non-induced cell line was slightly higher than the control, consistent with

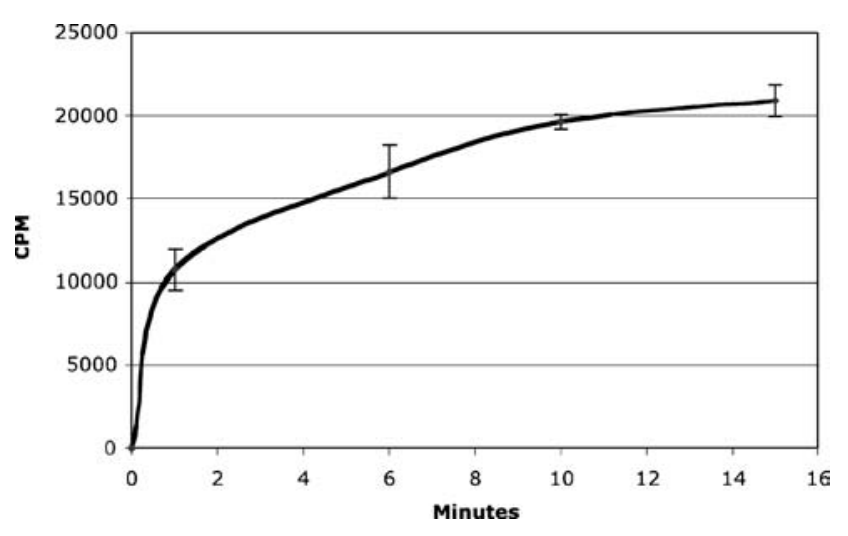

(a)

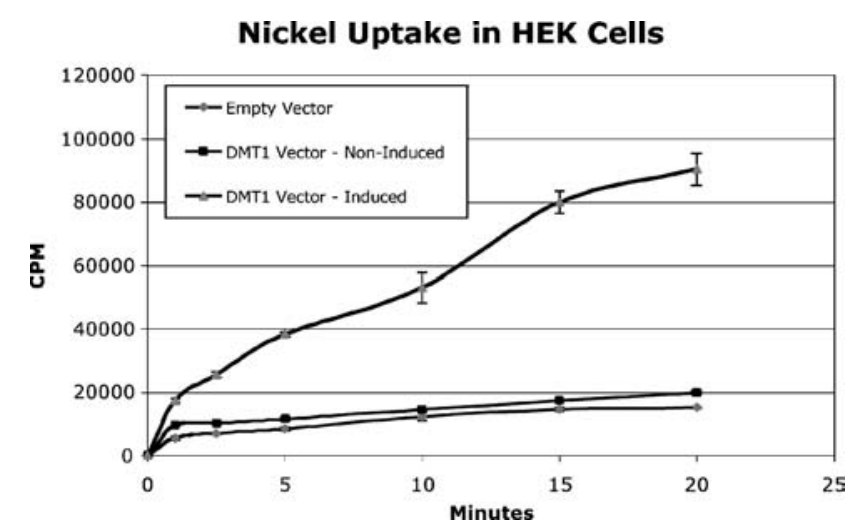

(b)

Fig. 1. Uptake of Nickel into A549 and HEK cells. (a) A549 cells expressing endogenous transporters were incubated for various times with ${ }^{63} \mathrm{NiCl}_{2}$. (b) HEK cells with the empty vector (v), the HEK cell line with the DMT1 expression vector but non-induced (2-ND), and the HEK cell line with the doxycycline induced DMT1 expression vector (2-D) were incubated for various times with ${ }^{63} \mathrm{NiCl}_{2}$. Incorporation into cells is shown on the ordinate as CPM.

a little expression from the strong CMV promoter even when doxycycline was absent.

\section{Soluble nickel blocks TfR-dependent and TfR-independent iron uptake}

Excessive iron is toxic to cells. Cells sequester extraneous iron by storing it in ferritin molecules. In Figs. $2 a$ and $b$ addition of both transferrin-bound iron and non-transferrinbound iron (NTBI) to A549 cells led to an increase in ferritin accumulation, in order to store the iron. In both cases, this induction could be blocked by addition of soluble nickel, indicating the exogenous iron was not accessible to the labile iron pool. These data suggest that soluble nickel can block the uptake of both transferrin-bound iron and NTBI. 


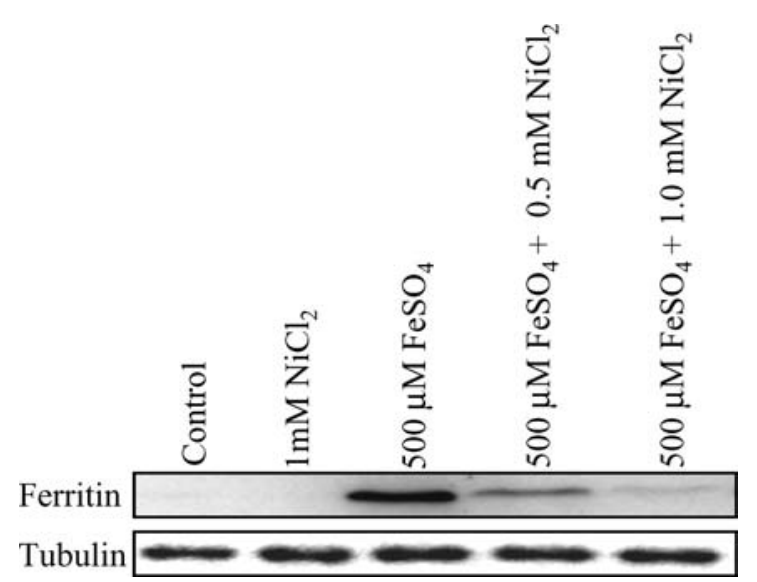

(a)

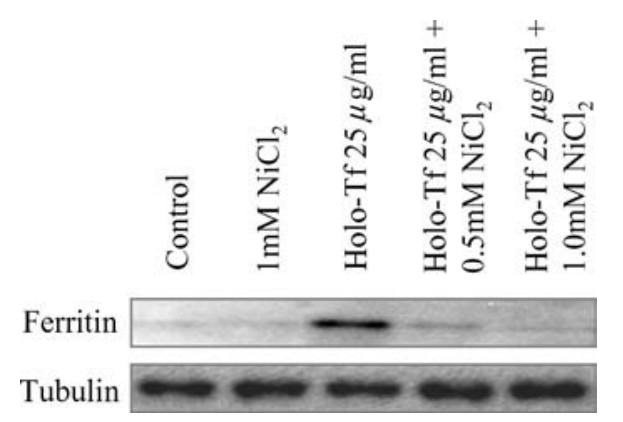

(b)

Fig. 2. Effects of nickel on ferritin induction by TfR bound iron and NTBI. (a) A549 cells were treated with $1 \mathrm{mM} \mathrm{NiCl} 2,500 \mu \mathrm{M} \mathrm{FeSO}_{4}, 500 \mu \mathrm{M}$ $\mathrm{FeSO}_{4}+500 \mu \mathrm{M} \mathrm{NiCl}_{2}, 500 \mu \mathrm{M} \mathrm{FeSO}_{4}+1 \mathrm{mM} \mathrm{NiCl}_{2}$ for $24 \mathrm{~h}$. (b) A549 cells were treated with $1 \mathrm{mM} \mathrm{NiCl}_{2}, 25 \mu \mathrm{g} / \mathrm{ml}$ Holo-transferrin, $25 \mu \mathrm{g} / \mathrm{ml}$ Holo-transferrin $+500 \mu \mathrm{M} \mathrm{NiCl}_{2}, 25 \mu \mathrm{g} / \mathrm{ml}$ Holo-transferrin $+1 \mathrm{mM} \mathrm{NiCl}_{2}$ for $24 \mathrm{~h}$. Cellular protein extracts were isolated as described in the section on 'Materials and methods.' Thirty micrograms of protein were subjected to western blot analysis and primary antibodies were used to determine the presence of ferritin light chain. Antibodies for $\alpha$-tubulin were used to confirm equal loading of proteins.

\section{Nickel decreases binding of VHL to the ODD domain of $H I F-1 \alpha$}

PHD's1-3 hydroxylate the ODD domain of HIF- $1 \alpha$. VHL can bind to the hydroxylated proline residues in the ODD domain of HIF- $1 \alpha$ and target it for degradation. When the prolyl hydroxylases are not functional, no hydroxylation of the proline residues in the ODD domain occurs and VHL will not bind. In Fig. 3, treatment of A549 cells with increasing concentrations of nickel strikingly decreased the ability of VHL to bind to the ODD domain of HIF- $1 \alpha$, indicating that nickel decreases the enzymatic activity of PHD1-3.

\section{Discussion}

Various mechanisms of nickel-induced carcinogenesis have been proposed including epigenetic changes/chromatin

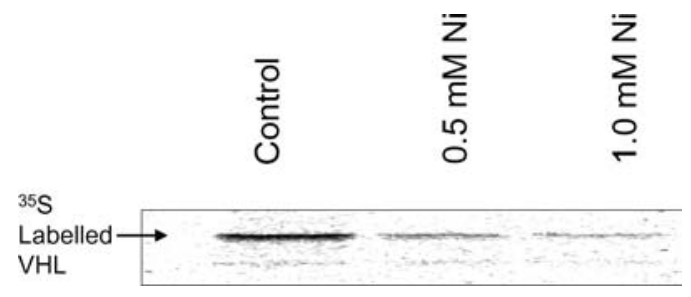

Fig. 3. Nickel decreases the binding of VHL to the ODD domain of HIF- $1 \alpha$. Glutathione purified GST-ODD was in vitro hydroxylated by cell extracts treated with $0.5 \mathrm{mM}$ and $1.0 \mathrm{mM} \mathrm{NiCl} 2 .{ }^{35} \mathrm{~S}$-labelled VHL was allowed to bind any hydroxylated-ODD. Bound VHL was pulled down and visualized by Western blot using ENLIGHTNING solution. Experiments were repeated three times and a representative gel was chosen for publication.

remodeling, signaling, oxidative stress, and interference with iron homeostasis. While there is no one definitive mechanism, all of the proposed mechanisms may play a role in initiating cancer or in the selection of initiated cells towards a cancerous phenotype. This paper focuses on the potential effects of soluble nickel on iron metabolism.

We have shown previously that nickel can decrease aconitase activity and increase IRP-1 binding activity, both changes associated with a decrease in cellular iron levels [13]. We have also previously reported that lower cellular iron levels can result from nickel competing with iron for entry into cells [13]. The ferritin data presented here provide support showing that nickel can prevent the accumulation of ferritin after exposure to either TfR-bound iron or NTBI. Additionally, we show that DMT1 can transport soluble nickel into cells. The significance of this result is strengthened by the observation that a G185R mutation in DMT1 attenuates nickel transport [22]. Once nickel enters the cell it may be able to compete with iron at an intracellular level and inactivate enzymes such as PHD1-3. This competition is a reasonable postulate because nickel and iron have similar atomic structures and ionic radii [23]. Additionally, intracellular competition between nickel and iron for iron binding sites on enzymes and proteins has previously been reported [24-26]. Therefore, the data presented in this manuscript, our previous reports, and publications from other labs suggest that nickel competes with iron not only for entry into cells at DMT1 but at an intracellular level as well.

Since it is well known that HIF-1 $\alpha$ is stabilized by nickel and its stability is controlled by the iron dependent enzymes, PHDs 1-3, we looked at the effect of nickel treatment on their activity. We measured PHD activity indirectly by assessing VHL binding to the ODD domain of HIF- $1 \alpha$. When cells were treated with nickel chloride, VHL binding the ODD domain substantially decreased compared to untreated cells. This change indicated that nickel decreased the activity of or inactivated the PHD enzymes. The exact mechanism by which nickel affects the PHD enzymes may involve decreased iron levels, intracellular competition at the iron-binding site 
of the enzyme, a combination of the aforementioned and/or other mechanisms. Another mechanism that has been proposed involves the nickel-induced depletion of intracellular ascorbate, required for function of the PHD enzymes [27]. Interestingly, ascorbate can affect iron homeostasis and can increase the availability of iron to enzymes [28-30]. A complex interplay is likely among ascorbate, iron and nickel that results in the inactivation of PHD's. Current research in this lab is investigating the exact mechanism by which $\mathrm{Ni}^{2+}$ exerts its inhibitory effect on PHD's.

A decrease in PHD activity and an increase in HIFdependent activity may be important factors in nickelinduced carcinogenesis. An initiated group of cells needs neo-vascularization in order to grow past a certain diameter [31]. Activation of HIF and its downstream angiogenic factors like vascular endothelial growth factor (VEGF) by nickel may be important steps in providing the signals needed for neo-vascularization. In other words, nickel may flip the "angiogenic switch" needed for tumor growth. The importance of the PHD's and VEGF in tumor growth was shown recently, when mice injected with cells overexpressing PHD1 developed smaller tumors than mice injected with cells containing an empty vector [32]. Regulation of HIF and its downstream targets provides an appealing target for tumor therapy. Understanding the mechanisms by which nickel activates HIFdependent genes may lead to a greater appreciation of possible therapeutic targets.

In conclusion, nickel can affect iron homeostasis in various ways. It can compete with iron for entry at an extracellular level, but may also compete for iron containing sites at an intracellular level. The ability of nickel to decrease or inactivate the enzyme activity of the iron-containing PHD enzymes may play an important role in nickel-induced tumor formation and carcinogenesis. The ability of nickel to affect other iron dependent enzymes and processes in the cell will be the subject of future investigation.

\section{Acknowledgements}

We thank Thomas Kluz for expert technical assistance. This work was supported by Grant Numbers ES05512, ES00260, ES10344, and T32-ES07324 from the National Institute of Environmental Health Sciences, CA16087 from the National Cancer Institute, DK 59794 from the National Institute of Diabetes, Digestive and Kidney Disease, and FP-916418010 from the Environmental Protection Agency.

\section{References}

1. International Agency for Research on Cancer I: Monographs on the Evaluation of Carcinogenic Risks to Humans: Chromium Nickel and Welding. Lyon, France, 1990
2. Kasprzak KS, Sunderman FW, Jr., Salnikow K: Nickel carcinogenesis. Mutat Res 533: 67-97, 2003

3. McEwan JC: Cytological monitoring of nickel sinter plant workers. Ann NY Acad Sci 271: 365-369, 1976

4. Roberts RS, Julian JA, Muir DC, Shannon HS: Cancer mortality associated with the high-temperature oxidation of nickel subsulfide. IARC Sci Publ, Vol. 53: 23-35, 1984

5. Costa M, Sutherland JE, Peng W, Salnikow K, Broday L, Kluz T: Molecular biology of nickel carcinogenesis. Mol Cell Biochem 222: 205-211, 2001

6. Anttila A, Pukkala E, Aitio A, Rantanen T, Karjalainen S: Update of cancer incidence among workers at a copper/nickel smelter and nickel refinery. Int Arch Occup Environ Health 71: 245-250, 1998

7. Grimsrud TK, Berge SR, Haldorsen T, Andersen A: Exposure to different forms of nickel and risk of lung cancer. Am J Epidemiol 156: 1123-1132, 2002

8. Grimsrud TK, Berge SR, Martinsen JI, Andersen A: Lung cancer incidence among Norwegian nickel-refinery workers 1953-2000. J Environ Monit 5: 190-197, 2003

9. Gunshin H, Mackenzie B, Berger UV, Gunshin Y, Romero MF, Boron WF, Nussberger S, Gollan JL, Hediger MA: Cloning and characterization of a mammalian proton-coupled metal-ion transporter. Nature 388: 482-488, 1997

10. Garrick MD, Dolan KG, Horbinski C, Ghio AJ, Higgins D, Porubcin M, Moore EG, Hainsworth LN, Umbreit JN, Conrad ME, Feng L, Lis A, Roth JA, Singleton S, Garrick LM: DMT1: A mammalian transporter for multiple metals. BioMetals 16: 41-54, 2003

11. Farcich EA, Morgan EH: Uptake of transferrin-bound and nontransferrin-bound iron by reticulocytes from the Belgrade laboratory rat: comparison with Wistar rat transferrin and reticulocytes. Am J Hematol 39: 9-14, 1992

12. Garrick LM, Dolan KG, Romano MA, Garrick MD: Non-transferrinbound iron uptake in Belgrade and normal rat erythroid cells. J Cell Physiol 178: 349-358, 1999

13. Chen H, Davidson T, Singleton S, Garrick MD, Costa M: Nickel decreases cellular iron level and converts cytosolic aconitase to iron-regulatory protein 1 in A549 cells. Toxicol Appl Pharmacol, in press.

14. Epstein AC, Gleadle JM, McNeill LA, Hewitson KS, O’Rourke J, Mole DR, Mukherji M, Metzen E, Wilson MI, Dhanda A, Tian YM, Masson N, Hamilton DL, Jaakkola P, Barstead R, Hodgkin J, Maxwell PH, Pugh CW, Schofield CJ, Ratcliffe PJ: C. elegans EGL-9 and mammalian homologs define a family of dioxygenases that regulate HIF by prolyl hydroxylation. Cell 107: 43-54, 2001

15. Jaakkola P, Mole DR, Tian YM, Wilson MI, Gielbert J, Gaskell SJ, Kriegsheim A, Hebestreit HF, Mukherji M, Schofield CJ, Maxwell PH, Pugh CW, Ratcliffe PJ: Targeting of HIF-alpha to the von Hippel-Lindau ubiquitylation complex by $\mathrm{O}_{2}$-regulated prolyl hydroxylation. Science 292: 468-472, 2001

16. Lando D, Peet DJ, Whelan DA, Gorman JJ, Whitelaw ML: Asparagine hydroxylation of the HIF transactivation domain a hypoxic switch. Science 295: 858-861, 2002

17. Salnikow K, Davidson T, Costa M: The role of hypoxia-inducible signaling pathway in nickel carcinogenesis. Environ Health Perspect 110: 831-834, 2002

18. Semenza GL: HIF-1 and human disease: one highly involved factor. Genes Dev 14: 1983-1991, 1983

19. Maxwell PH, Ratcliffe PJ: Oxygen sensors and angiogenesis. Semin Cell Dev Biol 13: 29-37, 2002

20. Wiesener MS, Maxwell PH: HIF and oxygen sensing: as important to life as the air we breathe? Ann Med 35: 183-190, 2003

21. D’Angelo G, Duplan E, Boyer N, Vigne P, Frelin C: Hypoxia upregulates prolyl hydroxylase activity: a feedback mechanism that limits 
HIF-1 responses during reoxygenation. J Biol Chem 278: 38183-38187, 2003

22. Knopfel M, Zhao L, Garrick MD: Transport of divalent transition-metal ions is lost in small-intestinal tissue of $\mathrm{b} / \mathrm{b}$ Belgrade rats. Biochemistry 44(9): 3454-3465, 2005

23. Maxwell P, Salnikow K: HIF-1: an oxygen and metal responsive transcription factor. Cancer Biol Ther 3: 29-35, 2004

24. Batie CJ, Ballou DP: Phthalate dioxygenase. Meth Enzymol 188: 61-70, 1990

25. Batie CJ, LaHaie E, Ballou DP: Purification and characterization of phthalate oxygenase and phthalate oxygenase reductase from Pseudomonas cepacia. J Biol Chem 262: 1510-1518, 1987

26. Oshiro S, Nozawa K, Hori M, Zhang C, Hashimoto Y, Kitajima S, Kawamura K: Modulation of iron regulatory protein-1 by various metals. Biochem Biophys Res Commun 290: 213-218, 2002

27. Salnikow K, Donald SP, Bruick RK, Zhitkovich A, Phang JM, Kasprzak KS: Depletion of intracellular ascorbate by the carcinogenic metals nickel and cobalt results in the induction of hypoxic stress. J Biol Chem 279: 40337-40344, 2004

28. Bridges KR, Hoffman KE: The effects of ascorbic acid on the intracellular metabolism of iron and ferritin. J Biol Chem 261: 14273-14277, 1986

29. Toth I, Rogers JT, McPhee JA, Elliott SM, Abramson SL, Bridges KR: Ascorbic acid enhances iron-induced ferritin translation in human leukemia and hepatoma cells. J Biol Chem 270: 2846-2852, 1995

30. Toth I, Bridges KR: Ascorbic acid enhances ferritin mRNA translation by an IRP/aconitase switch. J Biol Chem 270: 19540-19544, 1995

31. Hanahan D, Folkman J: Patterns and emerging mechanisms of the angiogenic switch during tumorigenesis. Cell 86: 353-364, 1996

32. Erez N, Milyavsky M, Eilam R, Shats I, Goldfinger N, Rotter V: Expression of prolyl-hydroxylase-1 (PHD1/EGLN2) suppresses hypoxia inducible factor-1alpha activation and inhibits tumor growth. Cancer Res 63: 8777-8783, 2003 